\title{
SELF-ASSESSMENT OF THE POSITIVE POTENTIAL OF ORGANISATION BY MANAGERS OF POLISH COMPANIES - RESEARCH RESULTS
}

\author{
Monika Chodorek ${ }^{\mathrm{a}}$ \\ ${ }^{a}$ Department of General Management, Faculty of Economic Sciences and \\ Management, Nicolaus Copernicus University, Torun, Poland, \\ e-mail: monchod@econ.umk.pl
}

\begin{abstract}
The article presents the research results obtained by the employees of the Faculty of Economic Sciences and Management research team at Nicolaus Copernicus University of Torun and the author of the article is its member. The research aims at defining the level of Positive Potential of Organisation (PPO) defined as a set up (condition, level, configuration) of organisations material and non-material resources stimulating Positive Culture and Positive Atmosphere of Organisation, where employees pro-developmental behaviours are shaped, in enterprises operating in Poland. In order to assess the level of PPO, there was a number of surveys conducted, in which representatives of the researched companies were asked to describe the level, at which each component of PPO applies to the organisational potential, by choosing one category in the scale ranging from "definitely does not apply" $(0 \%)$ to "definitely does apply" $(100 \%)$. The article contains a detailed characteristics of elementary components of PPO and the interpretation of their ratings, showing the gap between the condition of Polish companies and standard PPO.
\end{abstract}

Keywords: Positive Potential of Organisation

Paper Type: Research Paper

\section{Introduction}

The term of 'Positive Potential of Organisation' is a relatively new idea, which stems from the concept of development of organisation (Cameron, Dutton, Quinn, 2003). Organisations are constantly seeking sources of development, and these are increasingly difficult to be found. Those resting within organisation are primarily connected with the organisation employees and their particular behaviours which result in high performance and productivity of resources. Examples of such behaviours are: creativity, innovation, loyalty, constant training of employees, openness in expressing opinions, full motivation to work. Nevertheless, there needs to be proper atmosphere and organisational culture fostering workers' prodevelopmental behaviour to make such behaviours become apparent and customary at workplace (Kożusznik, 2007). Atmosphere and organisational culture, in turn, 
SELF-ASSESSMENT OF THE POSITIVE

Monika Chodorek

Figure 1.

Positive Potential of Organisation as a factor for prodevelopmental behaviours and organisational development Source:

Glińska-Neweś (2010) are determined by specific combination of material and non-material resources present in the company. That specific array of such resources, their condition, level, configuration is basic for creating positive culture and atmosphere of organisation, described as Positive Potential of Organisation. Cause and effect relationship between formerly mentioned terms can be illustrated in the graphic form presented on Figure 1.

The main issue subject to the research is characteristics of Positive Potential of Organisation present in enterprises operating in Poland.

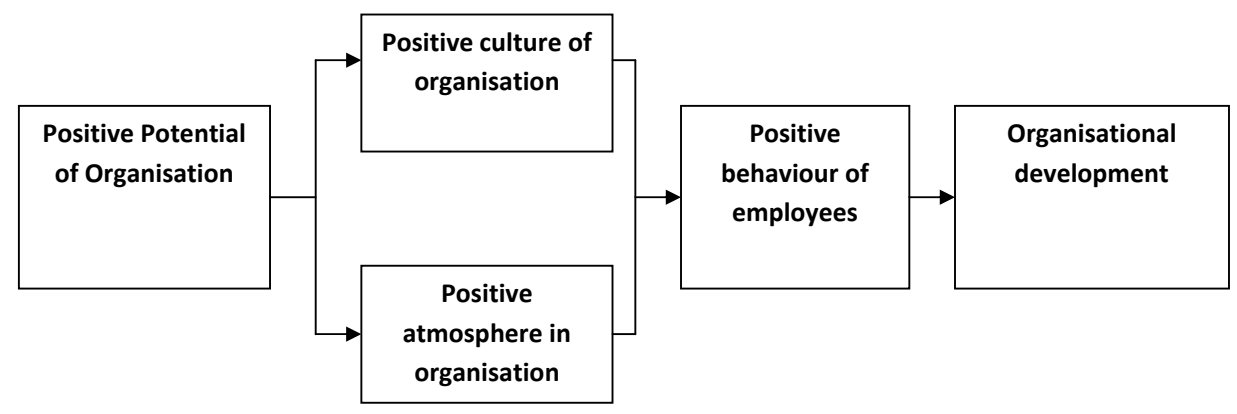

The concept of Positive Potential of Organisation has become more specific for the purpose of its detailed analysis. Consequently, the term of PPO has been divided into areas relevant to stimulation of pro developmental behaviour of organisation employees, and furthermore, elementary components have been distinguished within these areas, all of them constituting PPO as a whole.

\section{Detailed description of elementary components of PPO}

First group distinguished within PPO is connected with material resources. These resources create the environment in which an employee spends all day. That is why ensuring material comfort is essential to the employee's well-being in the organisation. This area comprises easy access to the sources of information (internet, intranet); completely equipped and attractive workplace; easy access to the sources of knowledge (libraries); attractive social infrastructure (bar, recreational facilities, kindergarten, nursery, clinic etc.) as well as ergonomic workplace. These elements make an employee feel safe and well at work and allow him to perform tasks properly.

Second group concerns nonmaterial resources connected with strategy, organisational structure, management of human resources, power and democracy of management, control, innovation, integration and corporate identity and the end leadership.

Within the area of strategy there are components which are connected with proper formulation of strategic targets, motivating employees to high performance. 
This area can be defined by the following factors: aligned strategy of company and employee interests; including employees' opinions in the process of formulating strategy; clearly defined and well communicated strategy; ambitious targets; well supported strategic aims; clearly defined stages of their realisation, their extent and deadlines; clearly defined tasks and responsibilities; fully and honestly reported target implementation. All the above factors allow better understanding of the targets presented to employees, higher accountability and involvement in target implementation.

Group of components referring to structure is strictly connected with elements enabling employees to act fast and react quickly to new situations and problems. Among these elements are: flat organizational structure and hierarchy; horizontal structure; possibility of assembling project teams, optimum formality - choice between necessity of precise and clear procedures and non formalised activities; the rule of 'internal customer' as well as efficient systems and channels of communication.

Elementary components of the area of PPO connected with human resources management are: clear and consistently used procedures (employment, replacement, assessment, career paths); considering applicants' skills and personality in selection procedures; appointing own employees to attractive positions as a priority; using rewards as a primary tool in motivational system, but allowing punishment when it is necessary (according to the criteria and extent regulated beforehand); in motivation system - allowing rewards - based on clearly formulated and widely known rules - in the form of shares in the company increasing value; in the assessment system - unambiguous, widely known, accepted and consistently used criteria (there is a possibility of them being co created with employees); assessment results strictly connected with human resources decisions; well developed, widely available training system, ensuring competence development to employees; subject matter of trainings advanced by employees and adjusted to their needs; high form and substance of trainings; usefulness of training for work performed in the company; attractive form of training; high requirements for applicants $=$ selectiveness of employment; flexible working hours and use of talent management system. These factors determine optimal clarity of employee's functioning system in the organisation at every stage of human resources process and they put pressure on ability to extend knowledge and skills in the company.

In the area connected with power and democracy of management there are components describing positive relationship on the superior- inferior level. They include: justification of decisions; consulting; delegation of authority; non formalized consulting; management by objectives; numerous direct channels of communication with superiors; using the rule which says that a less competent employee cannot manage the more competent one; manager as a coach and adviser
SELF-ASSESSMENT OF THE POSITIVE

Monika Chodorek 
SELF-ASSESSMENT OF THE POSITIVE

Monika Chodorek and not as a supervisor; zero nepotism (in employment, promotion, rewarding etc.). All the above describe superior- inferior relationships which are based on cooperation and not giving orders and obeying them.

Elementary components of the area of control describe clear controlling process as a basis for further development. This condition is characterised by the following components: main objective of any control aims at gaining information in order to improve work which is being assessed and check realisation of its outcome; frequency of controls adjusted to the character of work; criteria of control known in advance; measurable criteria; control system connected with motivation tools; great importance of self-assessment; availability of justification of control results and possibility of questioning it.

Into the group of elements concerning innovation fall the following components: considering and promoting pro-innovative behaviours in assessment systems; considering authorship of innovative ideas in human resources decisions (promotion, replacement etc.); attractive financial reward for authors of innovative and leading to innovation ideas; promoting pro-innovative attitudes as an example to follow; respecting individual authorship of ideas (not allowing superiors to steal or co-own their inferior's idea) and tolerance towards errors during innovative processes. These elements describe situation when pro - innovative attitude is accepted and promoted by management as a basis for development and means of competitive advantage.

The area of integration and corporate identity includes elements which allow building employees loyalty, raising employees morale and identity, and thus tightening ties between employees and organisation. This group comprises: voluntary participation in celebrating dates and events which are important for the company (anniversaries, successes etc.); trainings of joint liability and trust; attractive, clearly defined availability of leisure allowances; attractive and high standard healthcare benefits; assurance; ensuring employees access to information about the company (respectful of confidentiality of information and employees expectations); ensuring support in difficult situations; high reputation of the company; widely recognized company brands and attractive mission statement.

The last area of PPO involves components connected with leadership, and thus with the process which allows an individual to influence a group in order to achieve common goal (Cameron, 2008; Karaszewski, 2008). This complex process is a basis for success of organisation and its most important elements, which describe leaders are: ability to foresee; open-mindedness; drive; trustworthiness; accountability; ability to make impact and to inspire; empathy and courage.

The level of all the above elementary components of PPO process was thoroughly researched by the team in which the author participated in. Their findings are presented in the following part of the paper. 


\section{Assessment of the condition of Positive Potential of Organisation in} companies subject to the research

The assessment of PPO in companies was carried out in the form of a survey. Representatives of researched companies were asked to describe the importance of each component of PPO in defining PPO as a factor determining potential of organization by choosing from the category "definitely not" $(0 \%)$ to "definitely yes" $(100 \%)$.

Positive Potential of Polish companies was assessed at an average level of 67,13 , which is an average of assessment of each of the areas included in PPO (see Figure 2). In reference to the maximum rating of $100 \%$, the attained rating shows that there is a large area in Polish companies for improvement or change.

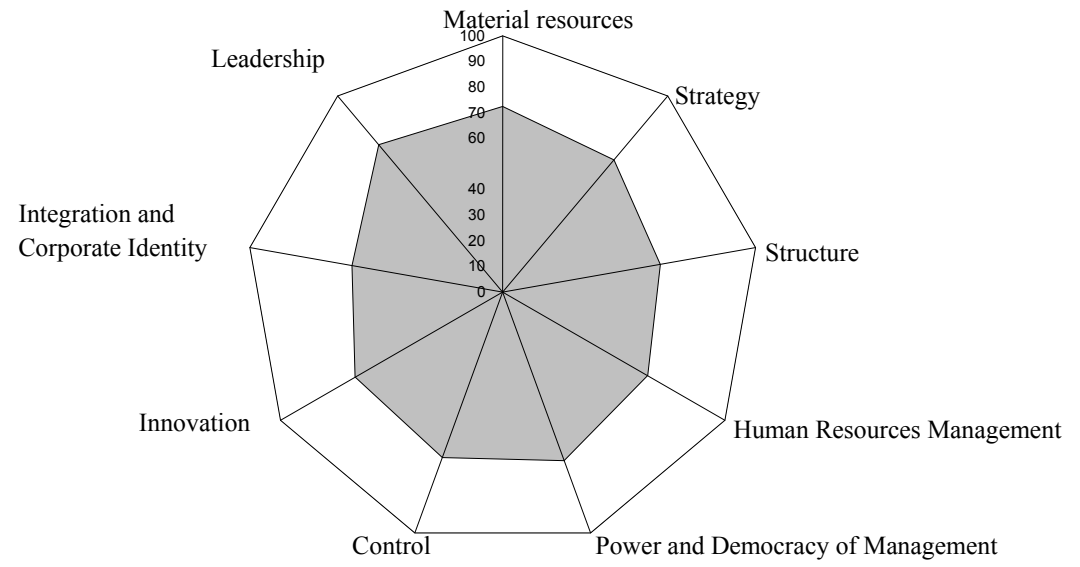

In the group of components connected with material resources, easy access to the sources of information (85.58) and completely equipped and attractive workplace (80.78) are most highly rated. This result suggests that Polish employees are rather satisfied with accessibility of sources of information, as well as material conditions of their workplace. Lower rating was given to the ergonomics of work tools (76.31) and access to the sources of knowledge (72.21). In the day of the Internet availability, access to information should not arise problems. What seems to be problematic though, is the ability to use proper information for the well being of organisation when organisational knowledge is not systemised, updated, and there are no tools allowing sharing it. All that results in lower rating of the resources of knowledge. The lowest rating comes to social infrastructure (bar, leisure facilities, kindergarten, nursery, clinic etc.) (50.19), which means that such places are in high demand among employees of Polish companies. Obviously, such facilities are not indispensable. Nevertheless, they partake in creating comfort of workplace for employees (i.e. possibility of having a hot meal at work or using
SELF-ASSESSMENT OF THE POSITIVE

Monika Chodorek

Figure 2.

Positive Potential of Organisation-average level 
SELF-ASSESSMENT OF THE POSITIVE

Monika Chodorek cheaper recreational services). Availability of a company clinic or kindergarten contributes to the employee's feeling of safety. Thus, it is an important factor creating PPO. What is striking, though is that the scope of answers was very wide and varied. It proves that some companies lack attractive social infrastructure, while other ones are very well equipped in different facilities. It is hopeful then that this positive tendency is going to rise.

The average rating of PPO in the area of material resources is 72.56. It is second in rank assessment of the level of PPO components, which proves that it is much easier to shape and build specific and tangible material components than it is to create relationships among employees, their safety and feeling of being appreciated etc. This fact was described by A. Maslow, who having created the pyramid of needs showed that physiological needs are on the lowest level [Griffin R.W., 1998]. It is much easier to satisfy these needs by ensuring appropriate material status. It is much more difficult to satisfy the needs of higher level, such as love and belonging or self-actualization. It is also visible in the rating of PPO components, as all the areas (except one) connected with non material components received lower rating.

The group of components connected with strategy was rated at the average level of 67.42. Among the elements of this group the highest rating was applied to ambitious strategic targets (74.62), which allows us to presume that management of Polish companies make their employees aim high. It is obviously a very positive behaviour, as it is the only way to reach for more, and in this way, to develop. These ambitious targets create employees' need for self-development, self-improvement and raising qualifications. They constitute a drive for any innovation, have stimulating power and make employees enter new areas. In achieving high goals it is essential to establish clear objectives for each employee (71.44). Giving them direction to act eliminates unnecessary conflicts. Another component, such as clear reporting of stages of realisation of targets was also highly rated (70.77). The area of justification of strategic aims falls lower in the rank (67.31), the same as precise defining of stages of realisation, extend and deadlines (66.92). It is the average of problems which arise in the area of clear defining and communicating strategic aims to employees. This situation suggests that operational management in Polish companies is much better than strategic management and indicates lack of ability to use employees in strategic management. It can be well supported by the fact that the following components were poorly rated: aligned strategy of company and employee interests (62.98) and consulting and considering employees opinion in the process of formulating strategy (60.58). The conclusion is apparent - strategic aims are defined solely by management or with low level of participation of employees. It is clear that the organisational method of Management by Objectives is still not very popular in Polish companies. It is thus crucial to remember that joint (superiors and 
inferiors) establishment and negotiation of the company's objectives results in greater involvement and better realisation of commonly established aims, as the employees identify with the target they have set.

Another area assessed by the representatives subject to research was the area of structure and various solutions which affect employees' relationships and the most important process, which is decision making in the company. Unfortunately, this area is still one of the most poorly ranked (62.31), thus it should be expected that there are a lot of drawbacks and difficulties, which hinder building positive culture and atmosphere in the organisation. The highest rating in that area was given to the optimal formalisation, i.e. choice between precise and clear procedures and non formal activities (66.63). Despite the fact that this component was most highly rated, it still remains in the lower levels of ranking. This level of assessment proves that setting optimal formalisation remains a problematic and difficult area to compromise. Too much formalisation can create chaos in organisation and lead to excessively informal behaviours among employees, whereas too much formalisation restricts creative and innovative behaviours. It leads to problems with finding optimal solutions. Flat organisational structure and flat hierarchy generate a variety of positive management solutions. This structure facilitates and fastens information flow and minimizes the risk of distortion. It allows lower rank employees to function creatively, as the ideas generated on the lowest level have direct access to the superiors. In the companies subject to the research there is a tendency towards flattening the structure and hierarchy, which is a very positive phenomenon, but still remains in minority (64.42). On the basis of the structural problems arise other difficulties, connected with systems and channels of information, which are not effective enough (63.65), as well as those with possibility of free selection of project teams (59.71). Flexibility in selection of project teams is mostly practiced in flat, process-oriented structures, where horizontal perspective prevails. Polish companies lack horizontal orientation. It was the most poorly rated structure in the survey (56.25). The last aspect of the area of organisational structure crucial to PPO is the idea of 'internal customer'. Internal customer is a person inside the company who receives part of work performed by another person (internal supplier) and then adds value to this product or service in order to pass it to somebody else (Leland, Bailey, 1999). The basis of the idea aims at the fact that everyone should meet mutual expectations. It improves comfort of cooperation, employees' awareness and, as a result, the satisfaction of the final customer. Existence of internal customer was rated at 63.17 , which proves that this idea is not popular and rarely used in the companies subject to the research. In this area, rating was varied and peripheral. There are companies which use this idea successfully and there are other ones, which do not apply it at all.

Another complex area of PPO is the area of human resources. Average rating in this group is 65.15. There are many highly appreciated aspects in this area,
SELF-ASSESSMENT OF THE POSITIVE

Monika Chodorek 
SELF-ASSESSMENT OF THE POSITIVE

Monika Chodorek especially the fact that applicants' skills and personality are taken into account in the recruitment process (73.46). It is a basic aspect of successful human resources management, as it allows the company to select an employee to the position in the best possible way, and thereafter motivate them to work efficiently. The fact, which affects motivation of employees is that whenever there is a vacant position in the company, they have a priority in applying for the post (72.60). It is a very positive situation, as it raises employees morale, creates better atmosphere and increases employees loyalty etc. Furthermore, in researched companies employees are motivated by positive tools, which boost their involvement in work (72.60) [Buckingham M., 2007]. As it is widely known, positive motivation tools (reward) are far more effective than negative ones (punishment). Punishment deters people from improper behaviour but does not stimulate to better work. What Polish companies lack is the possibility for employees to benefit from the shares in the company increase of value, as a form of reward on clearly defined rules (50.10). This solution can motivate employees to greater involvement in work, as their remuneration becomes strictly connected with the company financial results, which makes them more responsible for its future performance. The representatives of companies also confirm adequacy of trainings (72.98), which visibly increase efficiency of work, and admit that trainings that take place in companies are on high level. Nevertheless, the subject matter is hardly ever consulted with employees, and only a small number of volunteers can participate in them (66.73). Thus, it is not a system which could ensure that all employees who wish to participate in trainings have possibility of developing their competences. Another aspect which needs a lot of improvement is the process of recruitment, replacement and assessment of employees. Procedures are not clear enough, not understandable and inconsistently used. Assessment systems lack clear, unambiguous and widely accepted by employees criteria (64.71). Similarly, promotion connected with assessment and replacement system, as well as career paths, are not clearly defined. It leads to an assumption that assessment results are not strictly connected with human resources decisions (62.79). Another element, which is rarely present in researched companies, is flexible working hours (57.02), which allows employees to reconcile private life with professional responsibilities in a much easier way. It is especially important for employees with small children. The component of PPO with the lowest rating in the area of human resources management is talent management system, which is rarely used in researched companies (45.77). The situation is clear, as the answers in the survey were peripheral. The system is either well known and used, or completely unknown and inexistent. In this area, there is a very important issue of ability to deal with people of extraordinarily high competences and intellectual properties. Such people, who are usually highly qualified specialists, are the most difficult to acquire and maintain. Talented employees, in turn, significantly affect the increase of the company's value and possess potential for development and 
holding high managerial positions (Borkowska, 2005). Besides, in connection with emigration of highly qualified blue collar workers, there is a problem of acquiring and maintaining employees on the lowest levels of organisation. Consequently, one of the challenges of contemporary management awaiting company executives is undertaking actions aimed at highly talented people, as it a basis for development differentiating company activities.

Another area of PPO assessed by companies subject to the research was the area of power and democracy of management, which was rated at the level of 69.96. In this area the component which was most highly appreciated was existence of numerous communication channels with superiors (76.63). It is a very positive situation, as direct contact between the superior and inferior gives possibility to build positive relationships and brings a lot of advantages to both sides. The superior has direct access to information from its source, and moreover, it enables him to control the employees behaviour in a discrete way. The employee, on the other hand, can instantaneously share his problems and expect help with solving them, as well as suggest innovative solutions and improvements, which can lead to changes in the organisation. Except that, direct contact with the superior can evoke a lot of positive emotions, which can affect the employees' motivation and professional involvement. Possibility of direct contact with the superior is connected with other highly ranked components, such as non formalised form of advisory or consulting superiors, which facilitates work and speeds up decision making process (72.12). Also fair treatment of employees (and avoiding praising family and friends) positively affects employees well being in the organisation (71.83). These areas should be subject to constant improvements and such behaviours should be promoted. Further rating shows that Polish companies lack democratic management. Employee is still not treated as the main source of the most important information about the company, process and position. Delegation of power is performed to limited extend (69.52). The question which arises is whether the problem stems from employees (not knowledgeable enough, lacking skills, who cannot be trusted with additional tasks) or autocratic managers distrustful of their inferiors. There can be various reasons of not using delegation of powers. Nevertheless, turbulent environment of contemporary organisations is increasingly imposing delegation on managers. The bigger, more complex organisation, acting in changeable environment, the bigger extend of delegation (Bieniok, 2004). Except that, managers' decisions are not well supported enough (66.73). Argumentation allows better understanding of undertaken decisions and makes an employee feel more appreciated and respected. Such positive emotions are present in the practise of target management. This issue has been described earlier in the part of the article concerning strategy.

Another area of research concerns control, which was rated at 68.77. Unfortunately, the process of controlling does not aim at acquisition of
SELF-ASSESSMENT OF THE POSITIVE

Monika Chodorek 
SELF-ASSESSMENT OF THE POSITIVE

Monika Chodorek information for improvement of assessed work (69.81) and this area needs a lot of improvement to make this least enjoyable management sub process valuable for organisation and employees. The basis for proper control system are clear and well known to employees criteria of control. This is what researched companies lack (67.50). If managers want to make employees feel safe it is crucial that the employees know how their work will be assessed. What is more, control brings measurable effects only when it is reinforced by motivation tools. This aspect needs improvement, as this combination of control and motivation was present only in $57 \%$ of companies subject to the research. It is a very poor rating. The question that arises at that point is what the control is for, if employees who do their job well are not rewarded, and those, whose tasks are improperly done do not get punished. Apart from that, there are no tools or solutions increasing selfmonitoring (66.25). The solution in the form of increasing employee's involvement and in the same way their accountability and self- control is much better than when superior controls employee's every task. A positive aspect of control is that employees in the companies subject to the research can refer to the control results and obtain full report from the controller (76.54). The problem lies in the fact that it is not known what can be further done with the control results.

The area of innovation in Polish companies subject to the research is also rated on medium level, as its rating amounts to 66.44. It is another area in need of improvement, as companies should intensify pro -innovative behaviour of their employees. There is one outstanding component in reference to its rating, which is connected with respect towards authorship of ideas. In most companies there was no case of stealing inferiors' ideas by their superiors (74.04). It proves management's honesty. Other components of the researched area were far more poorly rated. The lowest in the ranking fell component concerning financial rewards for authors of innovative and leading to innovation ideas (58.94). It proves that creative, innovative and outstanding employees are little appreciated financially. This situation does not foster or reinforce creative behaviour due to the fact that financial stimulus is a very important tool motivating to uncommon behaviour. Thus, looking at the fact that authors of innovative ideas are little or not at all appreciated financially, it is not surprising that level of innovation in Polish companies remains on such low level. Pro-innovative ideas must be rewarded (66.83) in order to become common and attractive to employees. Apart from that, to increase company innovative character (which is an essential component of competitive edge), its management needs to make pro innovative behaviour an example to follow for other employees (63.94), and consequently, properly reward innovative employees, take their attitude into deep consideration for promotion or repositioning, still being aware of the fact that error is part and parcel of innovation (68.75), and employee should not fear such situation. Such awareness and organisational solutions promoting pro - innovative attitudes are still unavailable 
in Polish companies. It may be connected with the fact that innovative activities are very costly, with high level of risk inscribed in them, which Polish companies simply cannot afford. On the other hand, it is offensive management, focussed on innovative activities that is perceived as a basis for global leadership ,nowadays. Thus, if the attitude of Polish managers does not change, Polish companies will remain a supplier in the global chain of creating added value.

Another area which was assessed in the survey was integration and corporate identity, which was rated at the lowest level of 59,58. It suggests that there is the biggest shortage of activities and organisational solutions stimulating pro developmental behaviour in the area of integration and corporate identity (activities aiming at tying employees with the company, building their loyalty, leading to employees identification with the company etc.). According to the representatives of researched companies, well recognised brand (77.98) and high reputation of the company (75.10) are crucial to building strong ties between employees and their company. The fact is that it is easier and better to identify oneself with a company which is associated with good quality and highly recognised products. Another factor which ties employees with the company is joint celebration of events that are important to the company (76.25), such as anniversaries, achieved success etc. Such practices which connect people, allow them to build informal relationships, get to know one another better, become friends and good colleagues, and as a result, create a nice atmosphere for work. Nevertheless, there are too few additional activities undertaken by management which create bonds between an employee and their company, such as recreational allowance (57.02), insurance (46.35), attractive and high quality medical allowance (45.38), trainings of shared responsibility and trust (44.81), or psychological support (39.23). Employees still cannot obtain enough information about their company. This area was very poorly rated and resulted in low assessment of the area of integration and corporate identity.

The last area of research is leadership. It received the highest rating with an average of 75.04. Specifically, it is evaluation of leadership characteristics of Polish managers. The results that have been obtained need to be interpreted very carefully as they are based on self-assessment. It is extremely difficult not to be biased in the subject of oneself. Consequently, there was high rating given to all the characteristics assessed in this area. The highest rates in the area of PPO were applied to accountability (81.25) (higher rates were only given to access to information in the area of material resources). Polish managers are not only responsible, but determined (78.46), trustworthy (77.31), charismatic (75.10) and open-minded, brave (73.65) and inspiring (73.56) as well. They also have an ability to foresee the future (73.17). Surprisingly enough, they all consider empathy the least important characteristic. It seems then that they do not care what others think and feel, and their employees' emotions are of no concern to them. The question that arises, then, is how they can build trust, which is the basis
SELF-ASSESSMENT OF THE POSITIVE

Monika Chodorek 
SELF-ASSESSMENT OF THE POSITIVE

Monika Chodorek for influencing and inspiring others, without being capable of sympathising with them? Obviously, employees can be also influenced with the use of power, but such situation falls outside the idea of PPO.

\section{Conclusion}

As the research shows, the level of PPO in Polish companies is still insufficient. In many areas, there should be a variety of improvements introduced, in order to increase the level of PPO in Polish companies. Managers expectations towards Polish employees are very high. Thus, to increase employees creativity, ambitiousness, loyalty, motivation, innovation etc, they need to feel important for the company, feel that their opinion is taken into consideration in decision making processes and have a sense of safety. Only in such conditions the behaviour that is expected from them may be unleashed. Obviously, the ratings of the level of specific components of PPO that were obtained should be treated with some caution, due to the fact that self- assessment may be biased (given too high or too low ratings). It becomes even more curious when it is based on the comparison of the ratings of components of PPO according to Polish managers, in relation to the ratings from the Japanese and French managers of companies. French or Japanese companies outperform Polish enterprises, but their managers are far more critical towards the level of PPO in many areas than Polish ones. There is a question then, where these differences stem from? Is this real picture of the actual condition or is it a result of cultural differences in self-assessment?

\section{References}

Bieniok H. (2004), Metody sprawnego zarzqdzania, Placet, Warszawa.

Borkowska S. (ed.) (2005), Zarzqdzanie talentami, IPiSS, Warszawa.

Buckingham M. (2007), Go. Put Your Strengths to Work, Free Press, New York.

Cameron K.S., Dutton J.E., Quinn R.E. (Ed.) (2003), Positive Organizational Scholarship: Foundations of a New Discipline, Berrett-Koehler Publishers, Inc., San Francisco.

Cameron K.S., Positive Leadership. Strategies for Extraordinary Performance, BerrettKoehler Publishers, Inc., San Francisco.

Eland K., Bailey K. (1999), Obstuga klienta, Oficyna Wydawnicza Read Me, Warszawa.

Glińska-Neweś A. (2010), „Pozytywny Potencjał Organizacji jako prorozwojowa architektura zasobów przedsiębiorstwa”, in: M.J. Stankiewicz (ed.), Pozytywny Potencjat Organizacji. Wstęp do użytecznej teorii zarzq̨dzania, TNOiK, Toruń.

Griffin R.W. (1998), Podstawy zarzadzania organizacjami, PWN, Warszawa.

Karaszewski R. (2008), Przywództwo w środowisku globalnego biznesu, Wydawnictwo TNOiK, Torun.

Kożusznik B. (2007), Zachowania człowieka w organizacji, PWE, Warszawa.

Stankiewicz M.J. (Ed.) (2010), Pozytywny Potencjat Organizacji. Wstęp do użytecznej teorii zarządzania, TNOiK, Toruń. 